\title{
Impoverished Rearing Environment Alters Metabotropic Glutamate Receptor Expression and Function in the Prefrontal Cortex
}

\author{
Roberto I Melendez', Mary Lee Gregory', Michael T Bardo² and Peter W Kalivas*,I \\ 'Department of Physiology and Neuroscience, Medical University of South Carolina, Charleston, SC, USA; ${ }^{2}$ Department of Psychology, University \\ of Kentucky, Lexington, KY, USA
}

\begin{abstract}
Rearing rats in impoverished (IC) and enriched (EC) environmental conditions alters synaptic plasticity and cognitive processes. Metabotropic glutamate receptors (mGluRs) are known to play a key role in synaptic and behavioral plasticity. In the present study, the effect of rearing conditions on the expression of mGluR proteins in the prefrontal cortex (PFC) was assessed by immunoblotting. A significant difference in the content of prefrontal mGluRI and mGluR5 (ie group I) and mGluR2/3 (ie group II) was observed between IC and EC rats. To functionally characterize this difference, in vivo microdialysis was used to verify differences in mGluR regulation of extracellular glutamate in the PFC. The results indicate that the capacity of group I and II mGluRs to elevate extracellular glutamate levels was significantly blunted in the PFC of IC rats compared to either EC subjects, or rats reared in normal environmental conditions (ie NIH standards). Group II mGluR receptors regulate performance in a forced T-maze spatial memory task that involves the PFC, and IC rats demonstrated deficits in this task relative to EC rats. These data suggest that reduced mGluR transmission in the PFC produced by impoverished, relative to enriched, rearing environments may contribute to cognitive deficits.

Neuropsychopharmacology (2004) 29, 1980-1987, advance online publication, 9 June 2004; doi:I 0. I038/sj.npp. 1300507
\end{abstract}

Keywords: metabotropic glutamate receptors; immunoreactivity; microdialysis; rearing environments; enrichment

\section{INTRODUCTION}

Rats reared in complex, challenging environments ('enriched condition' or EC) develop reliable neurobiological differences from littermates reared alone without social or object interaction ('impoverished/isolated condition' or IC; Renner and Rosenzweig, 1987). Rearing in a relatively complex environment induces synaptogenesis (eg higher density of dendritic spines, enlargement of synaptic boutons, and other putative correlates of altered neurotransmission) throughout the cortex, as well as in the striatum and hippocampus (reviewed by Van Praag et al, 2000; Kolb and Whishaw, 1998). Conversely, IC animals are deprived of stimuli critical to behavioral and neurobiological development, resulting in altered neuronal morphology and deficits in complex problem-solving tasks (reviewed by Hall, 1998), including tasks requiring spatial

*Correspondence: Dr PW Kalivas, Medical University of South Carolina, Department of Physiology and Neuroscience, 173 Ashley Avenue, Suite 403 BSB, Charleston, SC 29425, USA, Tel: + I 843792 4400, E-mail: kalivasp@musc.edu.

Received 26 January 2004; revised 20 April 2004; accepted II May 2004

Online publication: I5 May 2004 at http://www.acnp.org/citations/ Npp05 I 50404032/default.pdf working memory (Martinez-Cue et al, 2002; Winterfeld et al, 1998).

Optimal performance in tasks requiring spatial working memory depends on intact dorsolateral prefrontal cortex in primates and medial prefrontal cortex (PFC) in rats (Goldman-Rakic, 1996; Aultman and Moghaddam, 2001). Within the PFC, both dopamine and glutamate transmission modulate working memory (Goldman-Rakic, 1996; Moghaddam et al, 1997; Romanides et al, 1999). Various studies show that group I and group II mGluRs are present in high density within the PFC (Romano et al, 1995; Wright et al, 2001; Xi et al, 2002b) and systemic or intra-PFC administration of drugs modulating group II metabotropic glutamate receptors (mGluR2/3) alters performance in a forced T-maze task requiring spatial working memory (Gregory et al, 2003; Aultman and Moghaddam, 2001; Moghaddam and Adams, 1998).

Metabotropic glutamate receptors are a family of G-protein-coupled receptors that have been divided into groups based on sequence similarities, coupling to intracellular messengers, and pharmacology (reviewed by Cartmell and Schoepp, 2000). Group I receptors (mGluR1 and mGluR5) are positively coupled to phospholipase $\mathrm{C}$ and are associated with the Homer family of intracellular proteins (Brakeman et al, 1997). Group II receptors (mGluR2/3) are negatively coupled to adenylate cyclase 
and regulate presynaptic glutamate release (Anwyl, 1999). Both electrophysiological and neurochemical studies show that stimulating group I or inhibiting group II mGluRs promotes the release of glutamate from presynaptic terminals and/or glia (Chen et al, 1997; Manzoni et al, 1997; Moroni et al, 1998; Cochilla and Alford, 1998; Fagni et al, 2000; Swanson et al, 2001; Xi et al, 2002a).

Given the differences between IC and EC subjects in memory tasks requiring intact $\mathrm{PFC}$ and the role of glutamate transmission in the $\mathrm{PFC}$ to regulate spatial working memory, the present study examined the effect of rearing environments on mGluR 1 , mGluR5, and mGluR2/3 protein immunoreactivity in the PFC. In addition, in vivo microdialysis was used to determine rearing impact on the capacity of mGluRs to regulate extracellular glutamate levels.

\section{MATERIALS AND METHODS}

\section{Animals}

Male Sprague-Dawley rats (Harlan, Indianapolis, IN) arrived in the laboratory at 21 days of age. The animal colony was in an AAALAC-approved animal facility with access to food and water ad libitum. Rooms were set on a 1212-h light cycle, with lights on at $0700 \mathrm{~h}$ and all experimentation was conducted during the light period. All protocols were approved by the Institutional Care and Animal Use Committee in compliance with NIH's Guide for the Care and Use of Laboratory Animals (National Academy Press, Washington DC, USA, 1996).

\section{Environmental Conditions}

The rationale for establishing each environmental condition was adapted as previously described by Bardo et al (2002). Upon arrival, rats were randomly assigned to an isolated (IC) or enriched (EC) environmental condition. IC rats were individually housed in a standard hanging metal cage $\left(16 \times 24 \times 18 \mathrm{~cm}^{3}\right)$ with wire mesh floor and front panel, and solid metal sides, back and top. IC rats were never exposed to toys or novel objects, nor handled during the exposure period. EC rats were housed in large metal cages $\left(60 \times 120 \times 45 \mathrm{~cm}^{3}\right)$ with cohorts $(10-12$ per cage). The EC environment contained pine chips on the floor and various toys made of metal or hard plastic. The objects were rearranged 4-5 days a week, with novel objects being introduced each day. Rats reared in normal environmental conditions (ie NC rats) were also used in the microdialysis experiment. NC rats were doubled-housed in a plastic tub $\left(16 \times 43 \times 18 \mathrm{~cm}^{3}\right)$ with pine chips on the floor, but no toys or novel objects available (ie standard NIH housing conditions). The exposure period for all the three environmental conditions was from 21 to 60 days of age prior to protein measurements, microdialysis, and behavioral testing. Separate groups of rats were used for the immunoblotting, dialysis, and behavioral experiments, and NC rats were available only for the microdialysis experiment.

\section{Tissue Preparation and Immunoblotting}

IC and EC rats ( $n=10 /$ group) were decapitated and the brains were rapidly removed and placed into an ice-cold brain mold (Braintree Scientific, Braintree, MA) for coronal sectioning. Coronal sections were laid on an ice-cold dissection plate and a 15-gauge blunt tissue punch was used to sample the medial PFC (dorsal or ventral; 2.7-3.7 mm from bregma) and striatum (1.2-1.7 $\mathrm{mm}$ from bregma). Dorsal PFC punches consisted primarily of anterior cingulate and prelimbic cortex, and ventral PFC punches consisted primarily of infralimbic cortex (Figure 1a; Paxinos and Watson, 1998). Striatal samples included the dorsolateral quadrant of the rostral half of the striatum. Samples were frozen at $-80^{\circ} \mathrm{C}$ until homogenized for protein analysis.

Tissue homogenization, electrophoresis and immunoblotting were conducted as described by $\mathrm{Xi}$ et al (2002b). Primary rabbit anti-rat antibodies for mGluR1, mGluR2/3 and mGluR5 (Upstate Biotechnology, Lake Placid, NY) were used in dilutions of $1: 1000,1: 1000$ or $1: 40000$, respectively. Labeled proteins were detected using an HRP-conjugated anti-rabbit secondary IgG (Upstate) diluted to either $1: 5000$ or $1: 10000$. Levels of actin were detected using goat anti-rat polyclonal IgG (Santa Cruz Biotech, Santa Cruz, CA) at 1:250 dilution and HRPconjugated donkey anti-goat IgG (Jackson ImmunoRes Labs, West Grove, PA) at 1:10000 dilution. Immunoreactivity was quantified by integrating band density $\mathrm{X}$ area using a photoimage scanner and densitometry software (NIH Image 1.60). Samples from IC rats were normalized to the average from EC rats obtained from the same gel.

\section{In Vivo Microdialysis}

IC, NC, and EC rats ( $n=5-6 /$ group) were bilaterally implanted with dialysis guide cannulae (20 gauge, $14 \mathrm{~mm}$; Small Parts, Roanoke, VA) over the PFC using the following coordinates according to the atlas of Paxinos and Watson (1998), using a $6^{\circ}$ angle from the vertical (in $\mathrm{mm}$; +2.7 anterior; + 1.1 lateral, -2.0 ventral). After surgery, rats were given 5 days to recover before testing. Microdialysis probes were constructed as described by Robinson and Whishaw (1988), except that both the inlet and outlet tubing consisted of fused silica. The active region of the dialysis membrane was between 2 and $3 \mathrm{~mm}$ in length and $\sim 0.22 \mathrm{~mm}$ in diameter. The night before the dialysis experiment, the probes were inserted through the guide cannulae into the prefrontal cortex. The next morning, the dialysis buffer (in mM: 5 glucose, $5 \mathrm{KCl}, 140 \mathrm{NaCl}, 1.4 \mathrm{CaCl}_{2}$, and $1.2 \mathrm{MgCl}_{2}$, and $0.5 \%$ phosphate-buffered saline to give a $\mathrm{pH}$ of 7.4) was advanced through the probe at a rate of $2 \mu \mathrm{l} /$ min via a syringe pump (Bioanalytical Systems, West Lafayette, IN). After $2 \mathrm{~h}$, baseline samples were collected. Liquid switches were used to minimize the pressure fluctuations while changing dialysis buffers with varying concentrations of drug.

The standard protocol used for microdialysis experiments involved the collection of three $20 \mathrm{~min}$ baseline samples, followed by three additional $20 \mathrm{~min}$ samples for each concentration of a given drug. Thus, multiple doses of each mGluR compound were administered in each rat. Dosage 
ranges of the various drugs were based upon the relative $\mathrm{IC}_{50}$ values for binding to the respective receptors (Schoepp et al, 1999). The mGluR1/5 agonist (RS)-3,5-dihydroxyphenylglicine $\left(\mathrm{DHPG} ; \mathrm{IC}_{50}=10 \mu \mathrm{M}\right)$ and the mGluR2/3 antagonist LY $341495\left(\mathrm{IC}_{50}=10 \mathrm{nM}\right)$ were purchased from Tocris (Ballwin, MO). All compounds were freshly prepared on the day of the experiment.

\section{Quantification of Glutamate}

Microdialysis samples were collected into vials containing $10 \mu \mathrm{l}$ of $0.05 \mathrm{M} \mathrm{HCl}$. The concentration of glutamate in the dialysis samples was determined using HPLC with fluorometric detection. Precolum derivatization of glutamate with $O$-phthalaldehyde was performed using a Gilson $231 \mathrm{XL}$ autosampler (Middleton, WI). The mobile phase consisted of $11 \%$ acetonitrile (v/v), $100 \mathrm{mM} \mathrm{Na} \mathrm{HPO}_{4}, 0.1 \mathrm{mM}$ EDTA, $\mathrm{pH}$ 6.04. Glutamate was separated using a reversed-phase column $(3 \mu \mathrm{m} ; 100 \times 4.2 \mathrm{~mm}$; Bioanalytical Systems, West Lafayette, IN), and was detected using a Shimadzu (Columbia, MD) 10RF-A fluorescence detector with an excitation wavelength of $320 \mathrm{~nm}$ and an emission wavelength of $400 \mathrm{~nm}$. The concentration of glutamate in the dialysis samples was quantified by comparing peak heights from samples and external standards.

\section{Histology}

After completion of the microdialysis experiments, rats were deeply anesthetized with an overdose of $\mathrm{CO}_{2}$ inhalation. The brains were removed and stored in $1 \%$ formalin for at least 1 week before sectioning. The tissue was then blocked, and coronal sections $(100 \mu \mathrm{M})$ were cut and stained with cresyl violet to verify probe placements. Only animals with probes located in the medial prefrontal cortex were included in the data analysis.

\section{Working Memory Task}

IC and EC rats ( $n=10$ /group) were trained to perform a forced-choice delayed-alternation task in a $\mathrm{T}$ maze (see Aultman and Moghaddam (2001) for details). The maze was constructed from black Plexiglas (alleys $30 \mathrm{~cm}$ high and $15 \mathrm{~cm}$ wide, main alley $50 \mathrm{~cm}$ long, start box $20 \mathrm{~cm}$ long, side arms $40 \mathrm{~cm}$ long). The start box was separated from the main arm by a guillotine door and the side arms were separated from the main arm by sliding doors. Movable doors were positioned between the start box and main alley and between the main alley and both side arms. Animals were habituated to the maze over a 3-day period in which each animal was allowed to roam throughout the maze freely for $10 \mathrm{~min}$, followed by 3 days of pre-training during which the animals were closed off in each side arm for $5 \mathrm{~min}$. Each rat was trained for 10 trials/day, with each trial consisting of two phases, the forced choice phase and free choice phase, separated by an intertrial delay (retention interval) ranging from 10 to $40 \mathrm{~s}$. At the beginning of each trial, both side arms contain sucrose pellet treats. For the forced phase, the rat was placed in the start box and allowed to enter the main alley. The door to only one of the side arms was opened, allowing the rat to enter and consume a sucrose pellet. During this time, the animal was enclosed for
$10 \mathrm{~s}$ and then returned to the start box for the intertrial delay. The rat was then allowed to re-enter the main arm for the free choice phase, when both side arms were open with a treat remaining in the side arm opposite to the arm previously selected. The rat made a choice and was enclosed in the selected arm for $10 \mathrm{~s}$ before being removed to a side cage for an additional $10 \mathrm{~s}$ before beginning a new trial (intertrial interval). The series of forced arm choices was $50 \%$ left arm and 50\% right arm selected at random daily. Animals were tested at each intertrial delay interval for 7 days, starting at $10 \mathrm{~s}$ and increasing by $10 \mathrm{~s}$ increments through a $40 \mathrm{~s}$ intertrial delay. Both EC and IC rats were tested on the same delay intervals in the same order. Values for each delay were obtained by averaging the performances of each group over the last 3 days of each delay.

\section{Statistical Analysis}

Western blot data were normalized to EC values in each blot, and statistically evaluated using separate one-way ANOVAs. The dialysis data were normalized to percent change from the average concentration in the baseline glutamate samples. Normalized data were analyzed using a two-way ANOVA (Group $\times$ Time) with repeated measures over time. Results showing significant interactions were followed by one-way ANOVA across Group at each 20-min interval, followed by Tukey's- $b$ test. Significant changes from baseline were determined by separate one-way ANOVAs with repeated measures over Time, followed by Fisher's LSD test. For the behavioral data, the percent correct responses were averaged over the last 3 days of each intertrial interval, and the EC and IC responses were compared using a two-way ANOVA with repeated measures over the intertrial interval. A confidence interval of $95 \%$ (0.05 alpha level) was used throughout.

\section{RESULTS}

\section{Group I and II mGluR Proteins are Different in the PFC of IC $v s$ EC Rats}

Normalized densitometry measurements of the expression of mGluR content in the PFC and striatum are shown in Table 1. Figure 1a illustrates the region of the dorsal PFC punches, which consisted primarily of anterior cingulate and prelimbic cortex; ventral PFC punches consisted primarily of infralimbic cortex (Paxinos and Watson, 1998). The dimer form of mGluR1 and mGluR5 proteins was significantly reduced in dorsal $\operatorname{PFC~}(\mathrm{F}(1,14)>4.1$, $p<0.02$ ) of IC compared with EC rats (Figure 2a). In contrast, no difference between IC and EC subjects was measured in the ventral PFC of IC rats. For mGluR1 protein, IC rats also had more mGluR 1 monomer band than EC rats in dorsal PFC $(\mathrm{F}(1,24)=4.1, p<0.05)$, and levels of mGluR5 monomer were equivalent. For $\mathrm{mGluR} 2 / 3$ protein, IC rats had less monomer than EC rats in the ventral PFC $(\mathrm{F}(1,27)=5.1, \quad p<0.03)$, but not the dorsal PFC (Figure 2b). In addition to the PFC, levels of mGluR were determined in the striatum and no significant difference was measured between EC and IC rats for the monomers or dimers of mGluR1, mGluR5, or mGluR2/3 (Table 1). Actin levels were equivalent between EC and IC subjects within 
Table I Impoverished Rearing Environment Alters Metabotropic Glutamate Receptor Immunoreactivity in the Medial Prefrontal Cortex

\begin{tabular}{|c|c|c|c|c|c|c|}
\hline Region & $\begin{array}{c}\text { mGluR I } \\
\text { Dimer }\end{array}$ & $\begin{array}{l}\text { mGluRI } \\
\text { Monomer }\end{array}$ & $\begin{array}{c}\text { mGluR5 } \\
\text { Dimer }\end{array}$ & $\begin{array}{l}\text { mGluR5 } \\
\text { Monomer }\end{array}$ & $\begin{array}{c}\text { mGluR2/3 } \\
\text { Dimer }\end{array}$ & $\begin{array}{l}\text { mGluR2/3 } \\
\text { Monomer }\end{array}$ \\
\hline VPFC & $81 \pm 9$ & $99 \pm 9$ & $87 \pm 16$ & $101 \pm 4$ & $104 \pm 3$ & $77 \pm 6 *$ \\
\hline Striatum & $84 \pm 33$ & $110 \pm 5$ & $88 \pm 26$ & $91 \pm 7$ & $102 \pm 7$ & $99 \pm 5$ \\
\hline
\end{tabular}

Results from densitometry measurements are presented as a percentage of rats reared in an enriched (EC) environment \pm SEM ( $n=6-14$ determinations). mGluR, metabotropic glutamate receptors; dPFC, dorsal prefrontal cortex; vPFC, ventral prefrontal cortex.

$* p<0.05$ compared to EC rats.

a

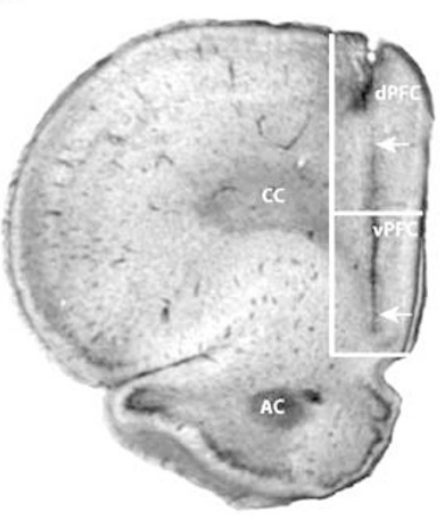

b

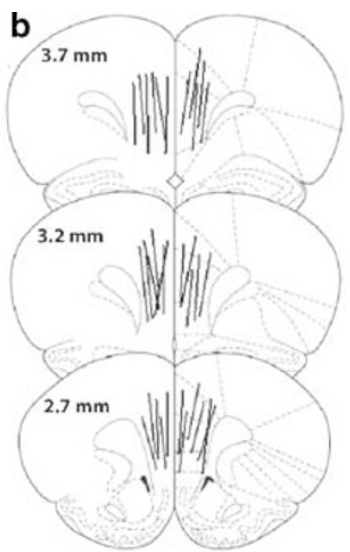

Figure I (a) Representative brain section of the medial prefrontal cortex of rats reared in EC and IC. Arrows indicate the beginning and ending of the dialysis membrane, which transverses along the dorsal and ventral region of the medial PFC. (b) Representative location of the microdialysis probes used in the study. Lines indicate the active portion of the dialysis membrane. The numbers indicate millimeters rostral to bregma according to the atlas of Paxinos and Watson (1998). Probe placements revealed that the probes traversed the dorsal (anterior cingulate and prelimbic) and ventral (infralimbic) region of the medial PFC. AC, anterior commissure; CC, corpus callosum; dPFV, dorsal prefrontal cortex; vPFC, ventral prefrontal cortex.

the dorsal and ventral PFC, and within the striatum (Figure 2a).

\section{Group I and II mGluR-Mediated Increase in Extracellular Glutamate Levels is Blunted in IC Rats}

Figure 1a shows the micrograph of a typical probe placement which transverses both the dorsal and ventral regions of the medial PFC. The representative locations of the dialysis membranes in the medial PFC of IC, NC, and EC rats used for analysis are shown in Figure 1b. Basal dialysate extracellular glutamate concentrations for the IC $(n=11)$, NC $(n=10)$, and EC $(n=12)$ groups were $40.1 \pm 3,30.2 \pm 5$, and $39.1 \pm 6 \mathrm{pmol} / \mathrm{sample}$, respectively. There were no significant differences in the basal levels of extracellular glutamate between groups $(\mathrm{F}(2,30)=1.47, p=0.24)$.

Time-course analysis of percent basal extracellular levels of glutamate during reverse microdialysis of the group I mGluR agonist DHPG is shown in Figure 3a. A two-way ANOVA with repeated measures over Time revealed a significant effect of Time $(\mathrm{F}(13,182)=10.3, p<0.001)$, Group $(\mathrm{F}(2,14)=3.5, p<0.05)$, and Time $\times$ Group interac- a

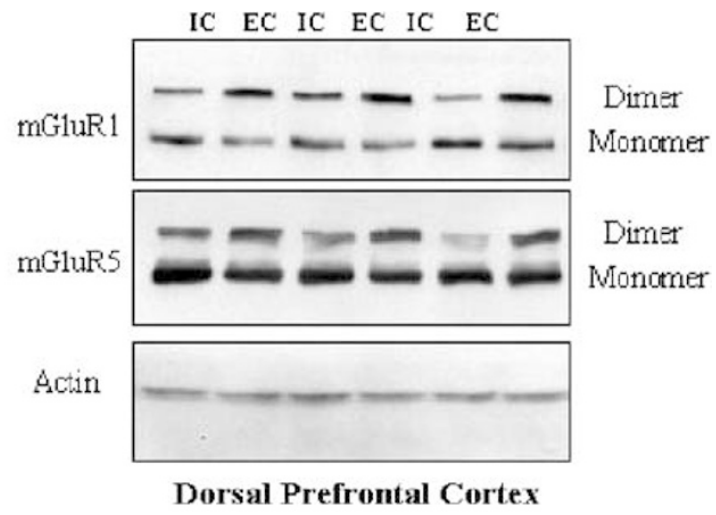

b IC EC IC EC IC EC

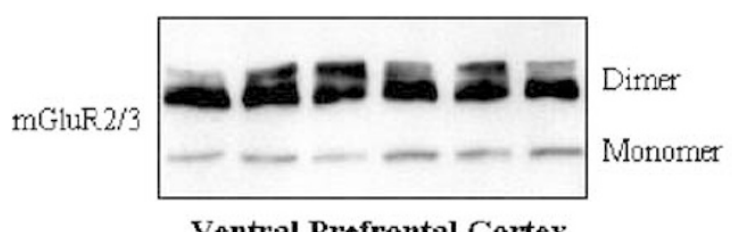

Ventral Prefrontal Cortex

Figure 2 Western blots of rats reared in EC and IC for group I and group II mGluRs in the medial PFC. (a) Representative immunoblots for mGluRI, mGluR5, and actin. Regardless of environmental treatment, immunoblots for both $\mathrm{mGluRI}$ and mGluR5 proteins yielded two distinct bands for each subtype $(\sim 150$ and $\sim 300 \mathrm{kDa})$. A significant reduction in the dimer form of mGluRI $(n=8)$ and mGluR5 $(n=12)$ and a significant increase in the monomer form of mGluRI $(n=14)$ within the dorsal region of the prefrontal cortex of IC rats were revealed (Table I). (b) Representative immunoblots for mGluR2/3. Regardless of environmental treatment, immunoblots for mGluR2/3 protein yielded two distinct bands $(\sim 100$ and $\sim 200 \mathrm{kDa}$ ) reflecting monomer and dimerized forms of mGluR2/3 (Xi et al, 2002b). A significant reduction was seen in the monomer form of mGluR2/3 $(n=14)$ within the ventral region of the prefrontal cortex.

tion $(\mathrm{F}(26,182)=1.6, p<0.04)$. Further analysis of the Time $\times$ Group interaction revealed that, compared to IC rats, 5 and $50 \mu \mathrm{M}$ DHPG significantly elevated the extracellular levels of glutamate in EC and NC rats $(p<0.05$; Tukey's $b$ ). Analysis by separate one-way ANOVAs with repeated measures across Time revealed that stimulation of group I mGluRs by DHPG (5 and $50 \mu \mathrm{M})$ induced a significant concentration-dependent increase above basal extracellular glutamate levels in EC $(n=6)(\mathrm{F}(13,65)=5.4$, $p<0.01)$ and $\mathrm{NC}(n=5)(\mathrm{F}(13,52)=4.4, p<0.01)$ rats. In contrast, IC rats $(n=6)$ showed no significant increase in extracellular glutamate in response to DHPG when com- 


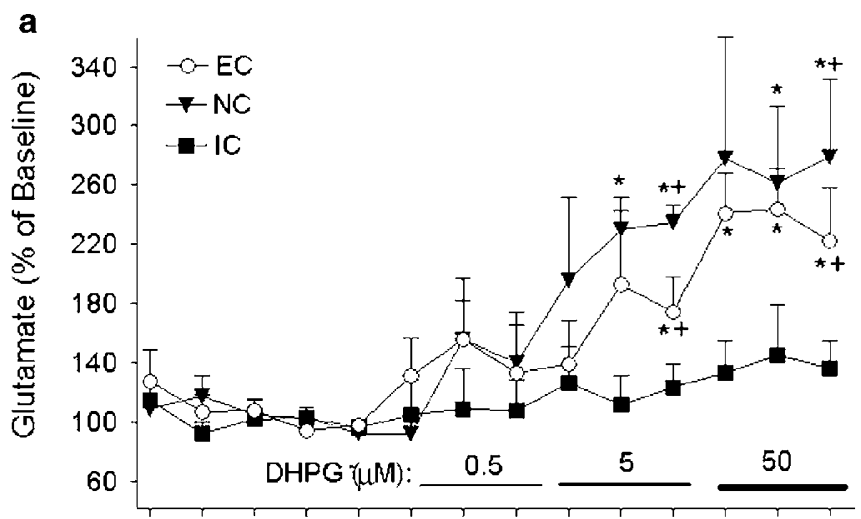

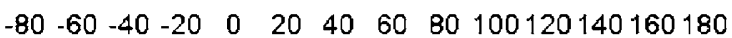

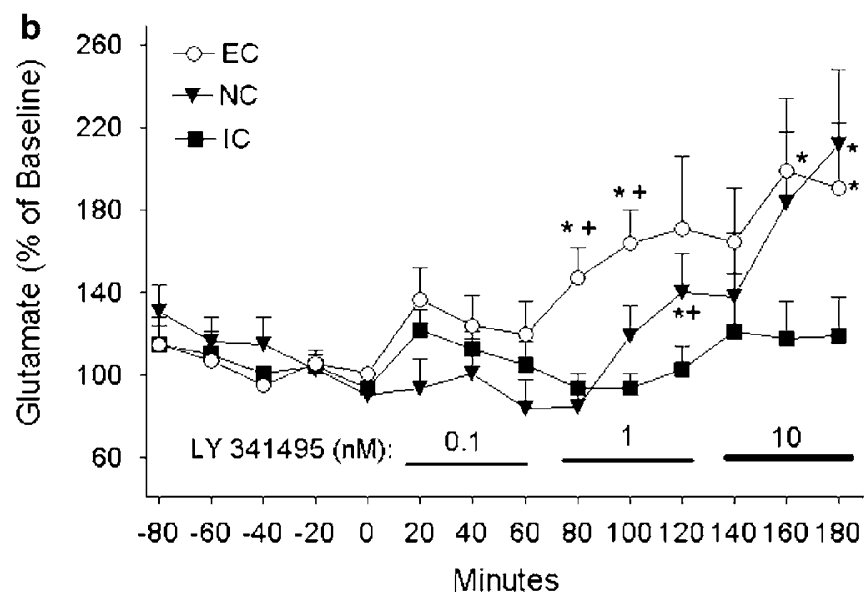

Figure 3 DHPG- and LY 34/495-induced elevation in extracellular levels of glutamate is blunted in the medial prefrontal cortex of rats reared in IC. (a) Using percent differences from baseline, analysis by two-way ANOVA with repeated measures on Time revealed that reverse microdialysis of DHPG dose-dependently increased extracellular glutamate levels in the PFC of rats reared in enriched conditions (EC; $n=6)$ and normal conditions (NC; $n=5)$, but not in IC $(n=6)$ rats. Further analysis revealed that $\mathrm{EC}$ and $\mathrm{NC}$ rats displayed significantly higher extracellular glutamate levels at 5 and $50 \mu \mathrm{M}$ DHPG. (b) Using percent differences from baseline, analysis by two-way ANOVA with repeated measures on Time revealed that reverse microdialysis of LY 341495 dose-dependently increased extracellular glutamate levels in the prefrontal cortex of EC $(n=6)$ and $\mathrm{NC}(n=6)$ rats, but not in IC $(n=5)$ rats. Further analysis revealed that $\mathrm{EC}$ and $\mathrm{NC}$ rats displayed significantly higher extracellular glutamate levels at I nM LY 34|495. $* p<0.05$, compared to baseline (post hoc LSD). ${ }^{+} p<0.05$ compared to IC rats (post hoc Tukey's b).

pared with baseline values over the concentration range tested $(\mathrm{F}(13,65)=0.9, p<0.6)$.

Time-course analysis of percent basal extracellular levels of glutamate during reverse microdialysis of the mGluR $2 / 3$ antagonist LY 341495 is shown in Figure 3b. A two-way ANOVA with repeated measures over Time revealed a significant effect of Time $(\mathrm{F}(13,169)=6.5, p<0.001)$ and Time $\times$ Group interaction $\quad(\mathrm{F}(26,169)=1.9, \quad p<0.02)$. Further analysis of the Time $\times$ Group interaction revealed that, compared to IC rats, $1 \mathrm{nM}$ LY 341495 significantly elevated the extracellular levels of glutamate in EC and NC rats $(p<0.05$; Tukey's $b)$. Analysis by separate one-way ANOVAs with repeated measures over Time revealed that inhibition of group II mGluRs by LY 341495 ( 1 and $10 \mathrm{nM})$ induced a significant concentration-dependent increase

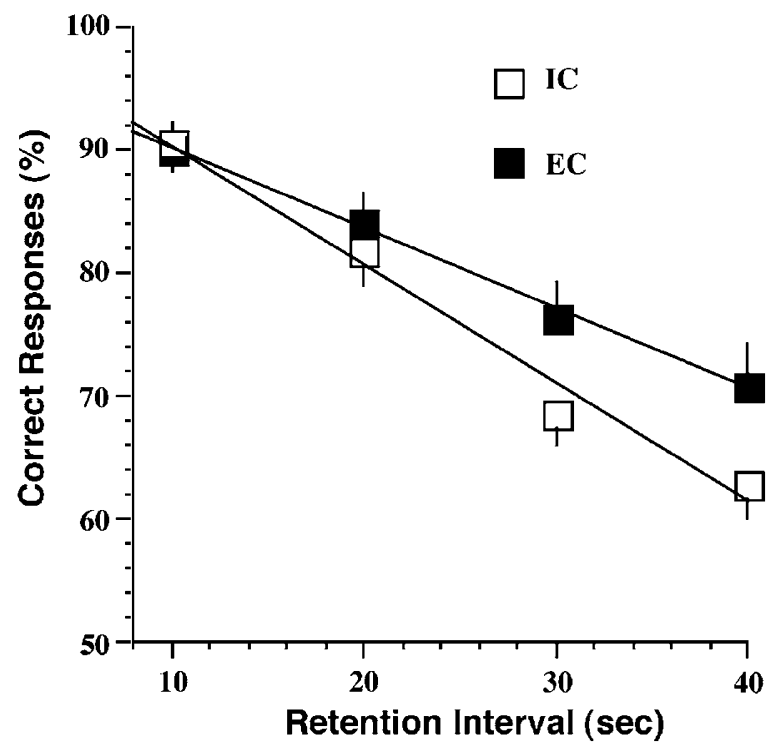

Figure 4 IC rats demonstrate impaired performance in spatial working memory compared to EC subjects. Once rats were trained to a forced choice delayed alternation task in a T-maze using a $10 \mathrm{~s}$ intertrial delay (retention interval), the intertrial delay was changed for 7-day periods. Each data point is the mean \pm SEM performance of the last 3 days at each intertrial interval ( $n=10 /$ group). A two-way ANOVA with repeated measures over intertrial interval revealed a significant effect of rearing environment

above basal extracellular glutamate levels in EC $(n=6)$ $(\mathrm{F}(13,65)=3.5, p<0.01)$ and $\mathrm{NC}(n=5) \quad(\mathrm{F}(13,52)=4.3$, $p<0.01)$ rats. In contrast, IC rats $(n=5)$ showed no significant increase in extracellular glutamate in response to LY 341495 when compared with baseline values over the concentration range tested $(\mathrm{F}(13,52)=0.7, p<0.7)$.

\section{IC Rats Show Working Memory Deficits Relative to EC Rats}

Performance in a forced-choice delayed alternation T-maze paradigm that depends on the integrity of the PFC (Aultman and Moghaddam, 2001) was compromised in IC rats relative to EC rats (Figure 4). As delay time was increased from 10 to $40 \mathrm{~s}$, there was a significant reduction in performance in subjects from both rearing environments $(\mathrm{F}(1,3)=29.7$, $p<0.001)$. However, while EC $(n=10)$ and IC $(n=10)$ subjects demonstrated equivalent task performance when intratrial delay was low (eg $10 \mathrm{~s}$ ), as the delay was increased performance deficits appeared in the IC group $(\mathrm{F}(1,18)=5.4, p=0.03)$. Although the interaction between delay time and rearing environment was not significant, the difference between the IC and EC subjects was positively correlated with increased delay time $\left(r^{2}=0.919, p=0.04\right)$, indicating that as the difficulty of the task increased the difference in performance deficits between groups became more pronounced.

\section{DISCUSSION}

The present study demonstrates that impoverished rearing conditions produce a significant attenuation in mGluR function in the PFC. The capacity of group I and II mGluRs 
to regulate the level of extracellular glutamate was reduced in IC rats. Moreover, the reduction in IC rats was paralleled by differences in the content of mGluR1, mGluR2/3, and mGluR5 in the PFC. Finally, these distinctions in mGluR protein and function appear to correlate with differences in T-maze performance, whereas IC rats demonstrated deficits in spatial working memory relative to EC subjects.

\section{Effects of Rearing Environment on Group I mGluRs}

The capacity of the group I mGluR agonist DHPG to elevate extracellular glutamate in the PFC was blunted in IC subjects. This functional difference between EC and IC rats was correlated with decreased mGluR1 and mGluR5 dimer and increased mGluR1 monomer content in the dorsal PFC of IC subjects. The dimer form of mGluR 1 and mGluR5 is the active form of the receptor capable of binding glutamate and signal transduction through IP3 receptor stimulation (Kunishima et al, 2000; Sato et al, 2003). Thus, the increased ratio of monomer to dimer in the IC rats implies decreased receptor signaling. This is consistent with the microdialysis data showing that DHPG less effectively increased extracellular glutamate in IC rats. Of note, the distinctions in protein content between IC and EC subjects were greater for mGluR1 than mGluR5, and, although DHPG does not distinguish between mGluR1 and mGluR5 (Schoepp et al, 1999), the release of glutamate by DHPG is primarily via mGluR1 receptor stimulation (Cochilla and Alford, 1998; Swanson et al, 2001).

\section{Effects of Rearing Environment on Group II mGluRs}

Similar to group I mGluRs, mGluR2/3 exists in the brain in both monomer and dimer forms, and the dimer form is predominant in PFC (Xi et al, 2002b). IC rats demonstrated reduced monomer content in the ventral $\mathrm{PFC}$ relative to $\mathrm{EC}$ subjects. Although the role of dimerization in mGluR2/3 ligand binding and signaling is not known, the microdialysis study revealed that apparent in vivo tone on mGluR2/3 was reduced in IC animals. Thus, as previously observed in the nucleus accumbens (Xi et al, 2002a), inhibition of mGluR2/3 caused a rise in extracellular glutamate in EC rats, presumably by removing glutamatergic tone on mGluR2/3 regulation of glutamate release from synaptic glutamate release and cysteine-glutamate exchange (Gereau and Conn, 1995; Baker et al, 2002). The altered mGluR2/3 monomer content and apparent equivalent levels of basal extracellular glutamate between IC and EC rats argue that reduced mGluR2/3 signaling, not altered extracellular glutamate levels, mediates the blunted effect in IC rats. Consistent with this possibility, following chronic cocaine administration, mGluR $2 / 3$ monomer content is reduced in the $\mathrm{PFC}$, and this is associated with reduced responsiveness to mGluR2/3 antagonists, as well as reduced mGluR2/3 GTP $\gamma$ S binding (Xi et al, 2002b). Nonetheless, as dialysis probes in the present study were not corrected for recovery of glutamate, it is possible that altered basal glutamate levels may also contribute to differential sensitivity of EC and IC subjects to mGluR2/3 inhibition.

\section{Effects of Rearing Environment on Working Memory}

The PFC has a pivotal role in the neural network subserving working memory (Goldman-Rakic, 1996). To our knowledge, four studies employing the EC/IC paradigm have assessed working memory and find that IC subjects show reduced performance (Juraska et al, 1984; Escorihuela et al, 1995; Winterfeld et al, 1998; Martinez-Cue et al, 2002). In the present study, working memory performance in IC rats was significantly impaired when assayed with a delayed alternation T-maze task that has been shown to depend on an intact PFC (Aultman and Moghaddam, 2001). Moreover, the distinction between IC and EC subjects was apparent at higher delay intervals, indicating a decreased ability to retain rather than encode information (Aultman and Moghaddam, 2001). Whether decreased mGluR function in the PFC of IC subjects is causal in the working memory deficits is unknown. Supporting the involvement of mGluRs in regulating working memory, stimulating mGluR2/3 directly in the PFC and systemic administration of an mGluR2/3 agonist diminishes working memory performance (Aultman and Moghaddam, 2001; Gregory et al, 2003). However, based on these findings, it might be anticipated that reduced mGluR2/3 function in IC subjects would improve the working memory performance. One explanation for this apparent paradox is indicated by the findings that increased extracellular glutamate in the PFC produces working memory deficits (Moghaddam et al, 1997). For example, administration of NMDA antagonists disrupt working memory by reducing glutamate with a release in the prefrontal cortex (Moghaddam et al, 1997), and this effect is reversed by reducing glutamate with an mGluR2/3 agonist (Moghaddam and Adams, 1998). Thus, decreased sensitivity of $\mathrm{mGluR} 2 / 3$ receptors in IC rats would diminish presynaptic regulation of glutamate release, thereby permitting increases in glutamate that could disrupt working memory.

\section{CONCLUSION}

The capacity of group I and II mGluRs to affect extracellular glutamate levels in the PFC was significantly blunted in IC rats relative to $\mathrm{EC}$ or $\mathrm{NC}$ rats. The reduced efficacy of group I and II mGluRs to regulate glutamate likely arises in part from the altered ratio of dimer to monomer forms of the receptors. Moreover, the distinctions in mGluRs between IC and EC subjects correlated with differences in performance in a T-maze task, which depends on intact PFC function and is modulated by $\mathrm{mGluR} 2 / 3$ receptors. Since rearing rats in an impoverished environment may mimic the effect of stress on brain development (Bremner, 1999; Heim and Nemeroff, 2001), this study poses a potential role for dysfunction of mGluR receptors in the PFC in neuropsychiatric disorders such as schizophrenia and addiction, which are influenced by stress and thought to involve PFC-associated cognitive deficits (Goldstein and Volkow, 2002; Moghaddam, 2002).

\section{ACKNOWLEDGEMENTS}

This work was supported in part by the National Institute of Health Grants MH-40817, DA-07288, and MH-070194. 


\section{REFERENCES}

Anwyl R (1999). Metabotropic glutamate receptors: electrophysiological properties and role in plasticity. Brain Res Brain Res Rev 29: 83-120.

Aultman JM, Moghaddam B (2001). Distinct contributions of glutamate and dopamine receptors to temporal aspects of rodent working memory using a clinically relevant task. Psychopharmacology (Berl) 153: 353-364.

Baker DA, Xi ZX, Shen H, Swanson CJ, Kalivas PW (2002). The origin and neuronal function of in vivo nonsynaptic glutamate. $J$ Neurosci 22: 9134-9141.

Bardo MT, Klebaur JE, Valone JM, Deaton C (2002). Environmental enrichment decreases intravenous self-administration of amphetamine in female and male rats. Psychopharmacology (Berl) 155: 278-284.

Brakeman PR, Lanahan AA, O'Brien R, Roche K, Barnes CA, Huganir RL et al (1997). Homer: a protein that selectively binds metabotropic glutamate receptors. Nature 386: 284-288.

Bremner JD (1999). Does stress damage the brain? Biol Psychiatry 45: 797-805.

Cartmell J, Schoepp DD (2000). Regulation of neurotransmitter release by metabotropic glutamate receptors. J Neurochem 75: 889-907.

Chen J, Backus KH, Deitmer J (1997). Intracellular calcium transients and potassium current oscillations evoked by glutamate in cultured rat astrocytes. J Neurosci 17: 7278-7287.

Cochilla AJ, Alford S (1998). Metabotropic glutamate receptormediated control of neurotransmitter release. Neuron 20: 1007-1016.

Escorihuela RM, Tobena A, Fernandez-Teruel A (1995). Environmental enrichment and postnatal handling prevent spatial learning deficits in aged hypoemotional (Roman high-avoidance) and hyperemotional (Roman low-avoidance) rats. Learn Mem 2: 40-48.

Fagni L, Chavis P, Ango F, Bockaert J (2000). Complex interactions between mGluRs, intracellular $\mathrm{Ca} 2+$ stores and ion channels in neurons. Trends Neurosci 23: 80-88.

Gereau IV RW, Conn PJ (1995). Multiple presynaptic metabotropic glutamate receptors modulate excitatory and inhibitory synaptic transmission in hippocampal area CA1. J Neurosci 15: 6879-6889.

Goldman-Rakic PS (1996). Regional and cellular fractionation of working memory. Proc Natl Acad Sci USA 93: 13473-13480.

Goldstein RZ, Volkow ND (2002). Drug addiction and its underlying neurobiological basis: neuroimaging evidence for the involvement of the frontal cortex. Am J Psychiatry 159: $1642-1652$.

Gregory ML, Stech NE, Owens RW, Kalivas PW (2003). Prefrontal group II metabotropic glutamate receptor activation decreases performance on a working memory task. Ann NY Acad Sci 1003: 405.

Hall FS (1998). Social deprivation of neonatal, adolescent, and adult rats has distinct neurochemical and behavioral consequences. Crit Rev Neurobiol 12: 129-162.

Heim C, Nemeroff CB (2001). The role of childhood trauma in the neurobiology of mood and anxiety disorders: preclinical and clinical studies. Biol Psychiatry 49: 1023-1039.

Juraska JM, Henderson C, Muller J (1984). Differential rearing experience, gender, and radial maze performance. Dev Psychobiol 17: 209-215.

Kolb B, Whishaw IQ (1998). Brain plasticity and behavior. Annu Rev Psychol 49: 43-64.

Kunishima N, Shimada Y, Tsuji Y, Sato T, Yamamoto M, Kumasaka $\mathrm{T}$ et al (2000). Structural basis of glutamate recognition by a dimeric metabotropic glutamate receptor. Nature 407: 971-977.

Manzoni O, Michel JM, Bockaert J (1997). Metabotropic glutamate receptors in the rat nucleus accumbens. Eur J Neurosci 9: $1514-1523$.

Martinez-Cue C, Baamonde C, Lumbreras M, Paz J, Davisson MT, Schmidt C et al (2002). Differential effects of environmental enrichment on behavior and learning of male and female Ts65Dn mice, a model for Down syndrome. Behav Brain Res 134: 185-200.

Moghaddam B (2002). Stress activation of glutamate neurotransmission in the prefrontal cortex: implications for dopamine-associated psychiatric disorders. Biol Psychiatry 51: 775-787.

Moghaddam B, Adams B, Verma A, Daly D (1997). Activation of glutamatergic neurotransmission by ketamine: a novel step in the pathway from NMDA receptor blockade to dopaminergic and cognitive disruptions associated with the prefrontal cortex. $J$ Neurosci 17: 2921-2927.

Moghaddam B, Adams BW (1998). Reversal of phencyclidine effects by a group II metabotropic glutamate receptor agonist in rats. Science 28: 1349-1352.

Moroni F, Cozzi A, Lombardi G, Sourtcheva S, Leonardi P, Carfi M et al (1998). Presynaptic mGlul type receptors potentiate transmitter output in the rat cortex. Eur J Pharmacol 347: 189-195.

Paxinos G, Watson C (1998). The Rat Brain in Stereotaxic Coordinates 4th edn. Academic Press: New York.

Renner MJ, Rosenzweig MR (1987). Enriched and Impoverished Environments: Effects of Brain and Behavior. Springer-Verlag: New York.

Robinson TE, Whishaw IQ (1988). Normalization of extracellular dopamine in striatum following recovery from a partial unilateral 6-OHDA lesion of the substantia nigra: a microdialysis study in freely moving rats. Brain Res 450: 209-224.

Romanides AJ, Duffy P, Kalivas PW (1999). Glutamatergic and dopaminergic afferents to the prefrontal cortex regulate spatial working memory in rats. Neuroscience 92: 97-106.

Romano C, Sesma MA, McDonald CT, O'Malley K, Van den Pol AN, Olney JW (1995). Distribution of metabotropic glutamate receptor mGluR5 immunoreactivity in rat brain. J Comp Neurol 355: 455-469.

Sato T, Shimada Y, Nagasawa N, Nakanishi S, Jingami H (2003). Amino acid mutagenesis of the ligand binding site and the dimer interface of the metabotropic glutamate receptor 1. Identificaiton of crucial residues for setting the activated state. J Biol Chem. 278: 4314-4321.

Schoepp DD, Jane DE, Monn JA (1999). Pharmacological agents acting at subtypes of metabotropic glutamate receptors. Neuropharmacology 38: 1431-1476.

Swanson CJ, Baker DA, Carson D, Worley PF, Kalivas PW (2001). Repeated cocaine administration attenuates group I metabotropic glutamate receptor-mediated glutamate release and behavioral activation: a potential role for Homer. J Neurosci 21: 9043-9052.

Van Praag H, Kempermann G, Gage FH (2000). Neural consequences of environmental enrichment. Nat Rev Neurosci 1: 191-198.

Winterfeld KT, Teuchert-Noodt G, Dawirs RR (1998). Social environment alters both ontogeny of dopamine innervation of the medial prefrontal cortex and maturation of working memory in gerbils (Meriones unguiculatus). J Neurosci Res 52: 201-209.

Wright RA, Arnold MB, Wheeler WJ, Ornstein PL, Schoepp DD (2001). ${ }^{3} \mathrm{H}$ ] LY341495 binding to group II metabotropic glutamate receptors in rat brain. J Pharmacol Exp Ther 298: 453-460. 
Xi Z, Ramamoorthy S, Baker DB, Shen H, Samuvel DJ, Kalivas PW (2002a). Modulation of group II metabotropic glutamate receptor signaling by chronic cocaine. J Pharmacol Exp Ther 303: 608-615.
Xi ZX, Baker DA, Shen H, Carson DS, Kalivas PW (2002b). Group II metabotropic glutamate receptors modulate extracellular glutamate in the nucleus accumbens. J Pharmacol Exp Ther 300: $162-171$. 